\title{
Public Green Space and Mental Health building Self-Esteem for Elderly Population in Dhaka
}

\author{
K M Atikur Rahman ${ }^{1 *}$, Pan Meiyu², Md. Abu Naim Shorkar ${ }^{3}$ \\ School of Sociology and Political Science, Shanghai University, Shanghai, CHINA-200444 \\ College of International Exchange, International Education, Shanghai University, Shanghai, CHINA-200444 \\ School of Economics, Shanghai University, Shanghai, CHINA-200444 \\ *Correspondence:atik73@shu.edu.cn
}

Abstract: Green public space immensely provides ecological soundness (ES), social resilience, social inclusiveness, mental health, self-esteem, and cultural prosperity from privileged class to lower ones. This research aims at estimating the effect of social services, safety, and infrastructural amenity in green space (parks) on mental health building self-esteem for elderly population. Data were collected from four parks out of 21 in Dhaka selected by systematic random sampling. Two-hundred and three elderly participants were picked up for survey using snowball sampling. The survey was conducted in a pre-structured questionnaire consisted of 40 close-ended questions. Data was analyzed applying ordinal logistic model, multivariate regression analysis, and Partial Least Square (PLS) -Path Modeling. The study explored several key findings-1) Infrastructural amenities impacted social services of parks; 2) Social services contributed positively to mental health boosting up self-esteem for elderly population. 3) Likewise, mental health for elderly population was affected by safety measure of green space. Dhaka requires constructing age-friendly parks to promote elderly mental health.

Keywords: green space; elderly population; mental health; self-esteem; social services; safety; Dhaka

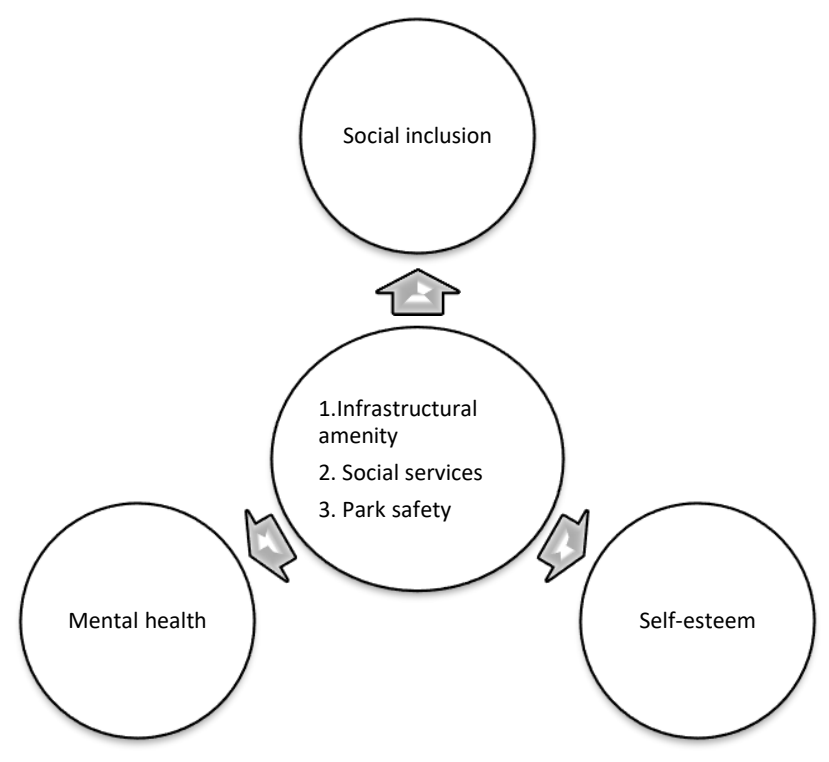

Figure: Graphical abstract 


\section{Introduction}

Self-esteem boosts-up life satisfaction for the population of all ages [1]. A study indicated that high self-esteem improves mental health linked to a better life performance that mitigates stress and anxiety for elderly population [2-4]. A person can cognitively be evaluated by life satisfaction that is a determinant of subjective wellbeing $[5,6]$. The psychological wellbeing of an elderly individual is influenced by social relationships [7,8]. Social relationship and inclusiveness is positively linked to one's life satisfaction[9-11] and socially excluded person shows various types of negative emotions such as loneliness, anxiety, depression, and jealousy[12]. In this way, they experience more reduced level of life satisfaction and selfesteem[11,13]. It is perceived that the social groups who are affected by societal exclusion in ignorance and rejection that lowers an individual's self-esteem, social adjustment[14], happiness, and psychological wellbeing[15].

Elderly people cope with the grief and companion loss of encouragement when a dear individual dies or detached[16,17], and if senior citizens get retired from work sometimes they have to confront a geographic transfer that causes a discard of their support network[17,18]. In this way, they have to undergo a psychological disturbance. Furthermore, some elderly people can suffer from physical challenges and chronic diseases, which limit their physical mobility and restrict their ability to social participation [19,20]. These aged people experience increased challenges of exclusion from society. An analysis showed that elderly people in Central and Eastern Europe are excluded more than other populations. They mostly experience health, material, and interpersonal isolation [21,22]. This exclusion decreases the productive contribution to society. Financial and emotional stress escorts them to hazardous states in the family as well as their social networks [23]. In this case, somebody assumes he is not socially accepted that lowers his self-esteem leading to emotional disturbance[24].

Elderly people have to experience loneliness as some family members shifted to other places due to profession. This shipment creates a greater loneliness causing psychiatric morbidity, physical impairment, low self-esteem, and the lack of self-confidence[25,26]. Sleep disturbance is a common phenomenon for elderly individuals and this disturbance increase the risk for morbidity and mortality[27], and reduces inflammation, particularly in individuals who 
experiences social exclusion or rejection [28]. Family members face difficulties with their professional duty due to the care of the patients[29]. Family deemed to be a key role player as caregiver to elderly people with psychological disturbance (e.g. dementia) [30] leading to their personal dishappiness. Nevertheless, recently marriage and family undergo a major transformation and those who are divorced and separated, face socially isolated and low selfesteem[31] experiencing mental stress. It is viewed that social isolation for elderly population is increasing along with the rise of their numbers.

Natural outdoor space (park) contributes immensely for elderly population in their physical and psychological health. Length of park-stay with physical and emotional activities is positively associated with elderly health[32]. People who live close to green space or park have less mental depression and anxiety. Green space provides restorative views and reduces hazardous exposures (noise, air pollution, and surface heat)[33]. Well-maintained green space and woodland improve social cohesion. Besides, social capital is associated with green infrastructure in urban areas[34]. Green exercise (exercise in park or nature) has a significant effect on self-esteem and positive mood. Self-esteem is higher in green exercise than club activities [35]. Through regular park usage, one can enhance his /her social networks that boostup his/her social acceptance promoting to self-esteem[36]. This study examines how public green space builds-up elderly self-esteem linked to social acceptance? We estimate how social and infrastructural services and safety in a park is linked to self-esteem for elderly individuals.

\subsection{Sociometer Theory and self-esteem to mental health}

Sociometer theory acts as an index to measure one's self-esteem by inclusion or rejection by others. According to the theory, human motivation, and high self-esteem is developed by an intimate connection to society or by acceptability among people. On the other hand, continuous rejection leads an individual to lower self-esteem [37]. Lower self-esteem decreases mental causing depression, loneliness, and anxiety for elderly population. A study showed the negative relationship between social exclusion and life satisfaction, resilience and self-esteem. On the other hand, there is an association between inclusion and life satisfaction and self-esteem [5]. Life satisfaction boosts-up psychological wellbeing creating happiness. Our study showed there is a positive relationship between green space and elderly self-esteem. According to sociometer theory, self-esteem for the elderly population is developed upon inclusion leading to sound 
mental health and. Public urban green space offers a natural setting for cultural programs and meeting options to people. Even western green parks accommodate people with handicaps and disabilities. A study showed the high-level contribution of green space on social inclusiveness. Disabled people expressed satisfaction that society goes through an assistance prone characteristic [38]. Public green space provides a social acceptance generating the inclusiveness of all aged people. Social inclusion boost-up self-esteem and happiness for the elderly population. Green space turned into more inclusive if the social facility, infrastructural services, and safety measures are ensured for the elderly or disabled users. Based on the sociometer theory, green space plays a vital role in social inclusion leading to healthy psychology.

\section{Material and Methods}

\subsection{Study setting}

This paper applied a two-stage sampling strategy consisting of systematic random and snowball sampling. Out of 21 parks in Dhaka, four were selected for this study using the systematic sampling; in addition, 203 participants were selected for survey through exponential non-discriminative snowball sampling. Dhaka was founded on the bank of the Buriganga River $\left(23.7107^{\circ} \mathrm{N}, 90.4090^{\circ} \mathrm{E}\right)$ and is progressively extending north due to overcrowding. 21 parks in were listed in geographical order from the south to north. Following the list, Bahadur Shah and Ramna Park were picked-up from south zone and Chandrima Udyan, and Gulshan Lake Park was chosen from north zone (table 1). Each fifth park was selected following systematic sampling formula. The formula was shown below:

$$
\text { Systematic sampling formula for interval }(i)=N / n=21 / 4=5.25
$$

Where $N$ denotes the size of the population, $n$ is the size of sample, and $i$ is the sample interval. Formula showed the interval is above 5 . So, $1^{\text {st }}, 6^{\text {th }}, 12 \mathrm{rd}, 17$ th positioned parks were chosen as samples. The selected parks have a diverse characteristic that represents all of the parks in Dhaka. The diversity includes size, spatial location, user social status, connectivity, and socio-infrastructural amenities. 


\subsection{Green spaces}

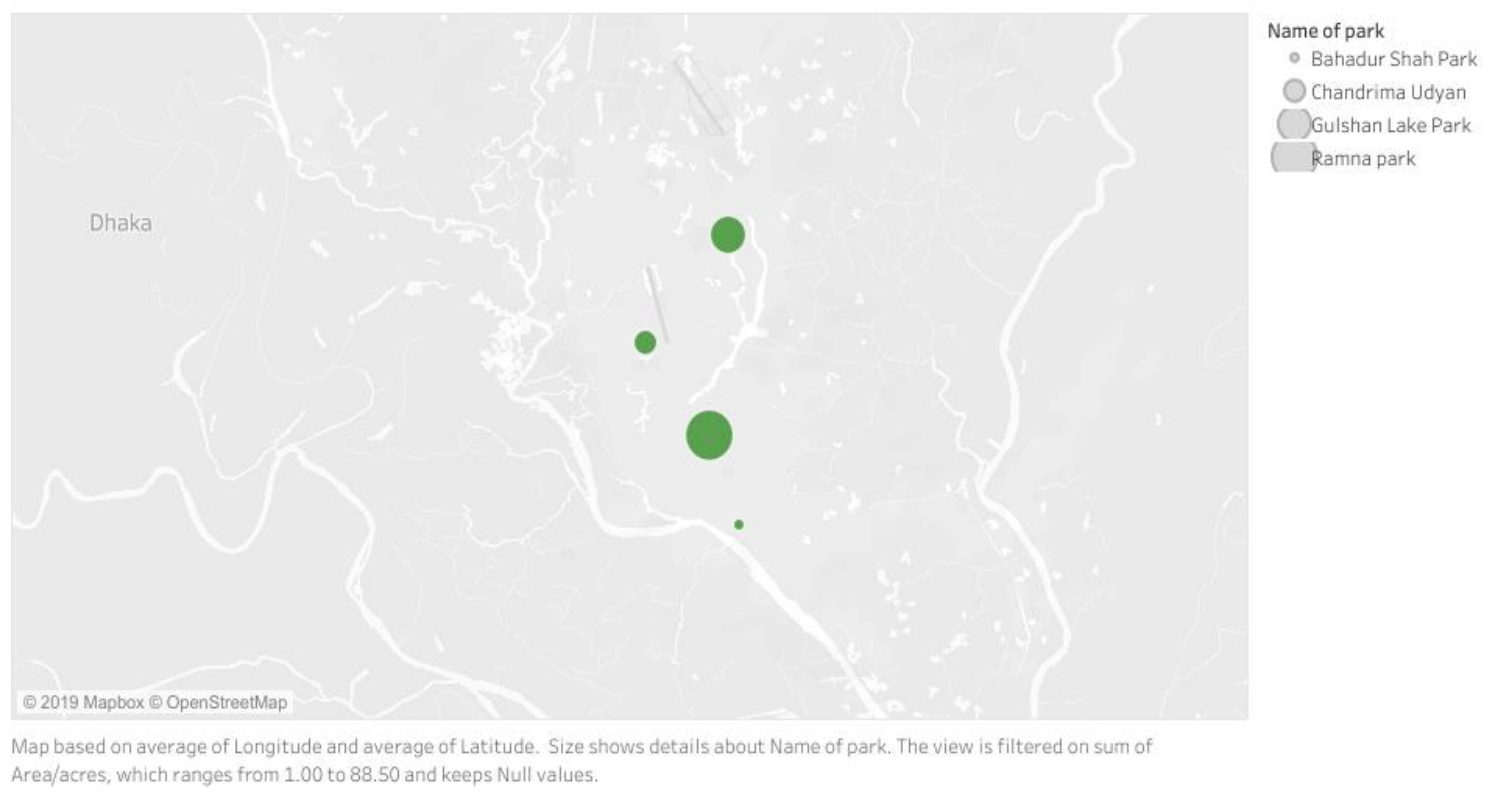

Figure 1. Geographical location of four parks (study areas)

The distinctive characteristics of these parks are diverse in terms of accessibility, size, the social status of regular users, key differences in management authority, various facilities etc. For instance, Bahadur Shah Park is maintained by Dhaka South City Corporation (DSCC), and its users are from the lower middle class. Meanwhile, Gulshan Society (a non-governmental organization) maintains Gulshan Lake Park, whose users are from the upper middle class. Ramna is an inclusive park, which accommodates the lower to privileged classes of people. The most significant numbers of users in the park belong to the middle class. This park is more spacious, which has a room of users from strangers to beggars. On the other hand, Chandrima Udyan is presently dropping its importance due to national political issues. Park users decrease gradually due to the lack of proper maintenance of facilities. The four parks were selected following diverse characters so that they can be suitable representatives of Dhaka.

\subsection{Study participants}

The study employed snowball sampling for the appropriate selection of potential respondents among elderly park users. The public parks are open to all without any formal restrictions, and the green patch does not record the entrance and exit information of park users; therefore, it was very challenging to reasonably calculate the number of users and their social 
identities. As such, snowball sampling was appropriate for participant selection. Snowball sampling is a distinguished, non-probability method of survey sample selection that can locate hidden and vulnerable populations[39], and it is widely used in places where it is hard to determine the population [40]. Moreover, our social survey intentionally targets elderly park users.

Elderly respondents were picked up using the exponential non-discriminative sampling technique. This method recruits participants, who do not recruit countless others, unlike exponential non-discriminative snowball sampling, in which each participant recommends other potential participants[41]. Some park users are unknown and uncertain but not completely hidden. All users of green parks have residential home but we did not survey household. As the residential identity of participants was unknown, so exponential non-discriminative snowball sampling was deemed appropriate for this study.

Table 1.Respondents sample composition of study area

\begin{tabular}{|c|c|c|c|c|c|c|c|c|c|}
\hline & & Gender & & Occupati & & & & Education & \\
\hline Name of park & Male & Female & $\begin{array}{l}\text { Govt. } \\
\text { job }\end{array}$ & $\begin{array}{l}\text { Nongovt. } \\
\text { Job }\end{array}$ & Business & $\begin{array}{l}\text { Unemployed } \\
\text { and others }\end{array}$ & $\begin{array}{l}1 \text { to } \\
12 \\
\text { grade }\end{array}$ & Undergraduate & $\begin{array}{l}\text { Post } \\
\text { graduate }\end{array}$ \\
\hline $\begin{array}{l}\text { Bahadur Shah } \\
\text { park }\end{array}$ & 39 & 13 & 5 & 7 & 21 & 19 & 27 & 20 & 5 \\
\hline Ramna park & 40 & 19 & 14 & 16 & 7 & 20 & 35 & 21 & 13 \\
\hline $\begin{array}{l}\text { Chandrima } \\
\text { Udyan }\end{array}$ & 36 & 18 & 12 & 14 & 13 & 15 & 19 & 17 & 18 \\
\hline $\begin{array}{l}\text { Gulshan Lake } \\
\text { park }\end{array}$ & 26 & 12 & 8 & 25 & 3 & 2 & 11 & 6 & 21 \\
\hline
\end{tabular}

Two hundred and three participants $(n=203)$ were interviewed (table 1). The ages of all respondents were more than 50 years. Two-thirds of them $(n=141)$ were males. More than half $(n=112)$ were undergraduate or up. Less than half $(n=92)$ were taken education ranged from 1 to 12 grades. The participants $(n=101)$ were employed in official jobs (government and nongovernment jobs) and a significant number of respondents $(n=56)$ were unemployed.

\subsection{Instruments for data collection}

A pre-structured questionnaire was used to explore participants' attitudes and satisfaction regarding parks. The questionnaire was produced followed by an extensive literature review and was confirmed by two senior academic experts on green space. The questionnaire was translated from English to Bengali by a certified translator. At that point, thirteen participants were interviewed as a pilot study and thus, around $15 \%$ of questions were changed to validate. Data 
collected from the pilot study were not included in the analysis. Observation (participant and non-participant) was implemented to investigate elderly activities in parks. A fieldwork note was employed to record data on participants' physical and social activities. The note was ratified by an academic expert. Observation focused on elderly social activities incorporated among different participants' groups. Data collected in observation implemented in the overview of study areas and in result discussion.

\subsection{Data collection}

This study was conducted in quantitative approach using primary data, which was collected from the sample parks. This was a self-administered survey using a pre-structured questionnaire. The questionnaire is consisted of 39 close-ended questions. Six questions were nominal, and the rest are ordinal variables with 5-point scales. Prior to the surveys, the research surveyor has introduced himself to participants, and a brief talk was delivered regarding the objectives of the study. After that, verbal consent was sought, and the respondents were asked to complete demographic information of their age, gender, educational attainment, monthly income, and employment status. At this stage, the interviewer explained the main contents (on parks' contribution to elderly life) of the interview schedule. Participants were provided interview schedules (printed paper sheet and a pen) to answer filling up one of the circles from each question. The interviews focused on participants' attitudes and satisfaction regarding parks. Suitable probing questions were invited if necessary. To extract further ideas from respondents, they were performed freedom to express other opinions on park contributions or setbacks. Interviews were conducted on sitting benches or walkways in the parks. Interviews were customarily performed after physical activities. Each interview lasted between 30 and 40 min. Field notes were produced during the interview. None of the interviews were redundant.

Observation was employed as a supplementary instrument for supporting data. Participant observation was conducted with conversation with park users and non-users (e. g. hawkers, staff) related to park activities. Conversation was carried out to explore park usability, quality of park, social atmosphere, user behavior and awareness of park use. Non-participant observation was applied to find out the status of infrastructural amenities, park use rules, and safety measures. This tool also used to investigate the socio-cultural and emotional activities of elderly population. 


\subsection{Data analysis}

The analytical process initiated with data familiarization by reading survey results repeatedly. Then, data were classified into demographics, social services, infrastructural amenities and safety measures for statistical analysis. Data were defined (creating labels and values for each variable) after inputting in IBM SPSS Statistics - version 23.0. Descriptive statistics computed the frequencies of variables. Inferential analysis includes logit model and path modeling. The conclusion was produced from the results of path modeling, which was operated for result triangulation. The models analyzed the correlation coefficient among variables. This study demonstrated a correlation between social ties for the elderly population and urban green space.

\section{Results}

\subsection{Respondents' social-demographic characteristics}

A majority of participants were males (about 67\%), and $33 \%$ were females. $36.5 \%$ of respondents received higher secondary education (table 2). A vital portion of respondents attained undergraduate degrees (around 59.1\%). 52.3\% of participants were employed in government, nongovernment positions, business, and self-services, and $47.8 \%$ were appointed in informal jobs. A majority of participants hold lower and lower-middle class. The table displayed that $47.8 \%$ of respondents' monthly income ranged from $\$ 118$ to $\$ 355$ only and $15.6 \%$ earned $\$ 356$ and up. In parks, $73.0 \%$ of elderly users boosted-up self-esteem, and 76\% were mentally sound. Altogether $23 \%$ of participants suffered from low self-esteem. Green Park constructed social capital and social inclusion among the elderly population. Most of the respondents (about $70.9 \%$ ) opined that parks were inclusive. But the societal atmosphere in parks was poorly maintained as $72.5 \%$ of participants were dissatisfied with the service.

\begin{tabular}{|c|c|c|c|c|}
\hline Variables & Score & Value label & $\mathrm{N}$ & $\begin{array}{l}\text { Valid } \\
\text { percent }\end{array}$ \\
\hline \multirow[t]{3}{*}{ Gender } & & Male & 382 & $67 \%$ \\
\hline & & Female & 193 & $33 \%$ \\
\hline & & Primary & 54 & $9.4 \%$ \\
\hline \multirow[t]{3}{*}{ Educational attainment } & & $\begin{array}{l}\text { Secondary and higher } \\
\text { secondary }\end{array}$ & 209 & $36.5 \%$ \\
\hline & & Undergraduate & 216 & $37.8 \%$ \\
\hline & & Post graduate & 93 & $16.3 \%$ \\
\hline
\end{tabular}




\begin{tabular}{|c|c|c|c|c|}
\hline & & Government service & 29 & $5.0 \%$ \\
\hline & & Nongovernment service & 86 & $14.9 \%$ \\
\hline \multirow[t]{6}{*}{ Occupation } & & Business & 105 & $18.2 \%$ \\
\hline & & Self-employment & 32 & $5.5 \%$ \\
\hline & & Unemployment & 50 & $8.7 \%$ \\
\hline & & Others & 276 & $47.8 \%$ \\
\hline & & $000-U S \$ 118$ & 157 & $27.2 \%$ \\
\hline & & US\$119-236 & 69 & $11.9 \%$ \\
\hline \multirow[t]{5}{*}{ Monthly income } & & US\$237-355 & 49 & $8.5 \%$ \\
\hline & & US\$356-473 & 13 & $2.2 \%$ \\
\hline & & US\$474-592 & 22 & $3.8 \%$ \\
\hline & & US\$595 and up & 55 & $9.5 \%$ \\
\hline & 1 & Extremely dissatisfied & 14 & $43.6 \%$ \\
\hline \multirow[t]{5}{*}{ Self-esteem } & 2 & Dissatisfied & 49 & $29.4 \%$ \\
\hline & 3 & Neutral & 57 & $13.0 \%$ \\
\hline & 4 & Satisfied & 131 & $11 \%$ \\
\hline & 5 & Extremely satisfied & 157 & $3 \%$ \\
\hline & 1 & Extremely dissatisfied & 11 & $47 \%$ \\
\hline \multirow[t]{5}{*}{ Mental health } & 2 & Dissatisfied & 49 & $29 \%$ \\
\hline & 3 & Neutral & 48 & $11 \%$ \\
\hline & 4 & Satisfied & 130 & $11 \%$ \\
\hline & 5 & Extremely satisfied & 20 & $2.5 \%$ \\
\hline & 1 & Not helpful at all & & \\
\hline \multirow[t]{5}{*}{ Social capital } & 2 & Not so helpful & 26 & $8.8 \%$ \\
\hline & 3 & Somewhat helpful & 60 & $20.3 \%$ \\
\hline & 4 & Helpful & 102 & $34.6 \%$ \\
\hline & 5 & Completely helpful & 107 & $36.3 \%$ \\
\hline & 1 & Extremely dissatisfied & 34 & $11.5 \%$ \\
\hline \multirow[t]{5}{*}{ Social inclusion } & 2 & Dissatisfied & 22 & $7.5 \%$ \\
\hline & 3 & Neutral & 29 & $9.8 \%$ \\
\hline & 4 & Satisfied & 82 & $27.8 \%$ \\
\hline & 5 & Extremely satisfied & 128 & $43.4 \%$ \\
\hline & 1 & Very poor & 75 & $25.4 \%$ \\
\hline \multirow[t]{4}{*}{ Social atmosphere } & 2 & poor & 139 & $47.1 \%$ \\
\hline & 3 & Neutral & 42 & $14.2 \%$ \\
\hline & 4 & Good & 23 & $7.8 \%$ \\
\hline & 5 & Very good & 16 & $5.4 \%$ \\
\hline
\end{tabular}




\subsection{Green space and self-esteem}

Different components in parks such as social services, infrastructural amenity, and safety measures affected elderly self-esteem (table 3). Social services (social atmosphere, number of peers, staying hour in the park, and frequency of participation in recreation programs) were associated with self-esteem for the elderly. This association was statistically significant. The friendly social atmosphere is positively linked to self-esteem as its coefficient value is 6.28 and the p-value is 0.01 . The poor number of peers was negatively connected to social esteem for elderly users, and the relationship was statistically significant at $1 \%$. Staying from one to 1 and $1 / 2$ hours in the park was positively tied into self-esteem. Besides, frequent participation in recreation programs delivered a positive impact on self-respect. Feeling safe and clean park possesses a sound effect on elderly social esteem. Distance from home to park between $1 / 4$ and $1 / 2$ promoted elderly self-esteem as its $\beta=2.97$ and $p=0.057$. Inadequately maintained infrastructural services like walkway, lighting, availability of community club, and drinking water lowered selfesteem for the elderly population. Lack of drinking water and poorly maintained park lighting retains a negative association between green space and elderly self-respect which had a statistical significance at a $1 \%$ level.

Table 3. Ordinal logit model: the contribution of park to elderly self-esteem

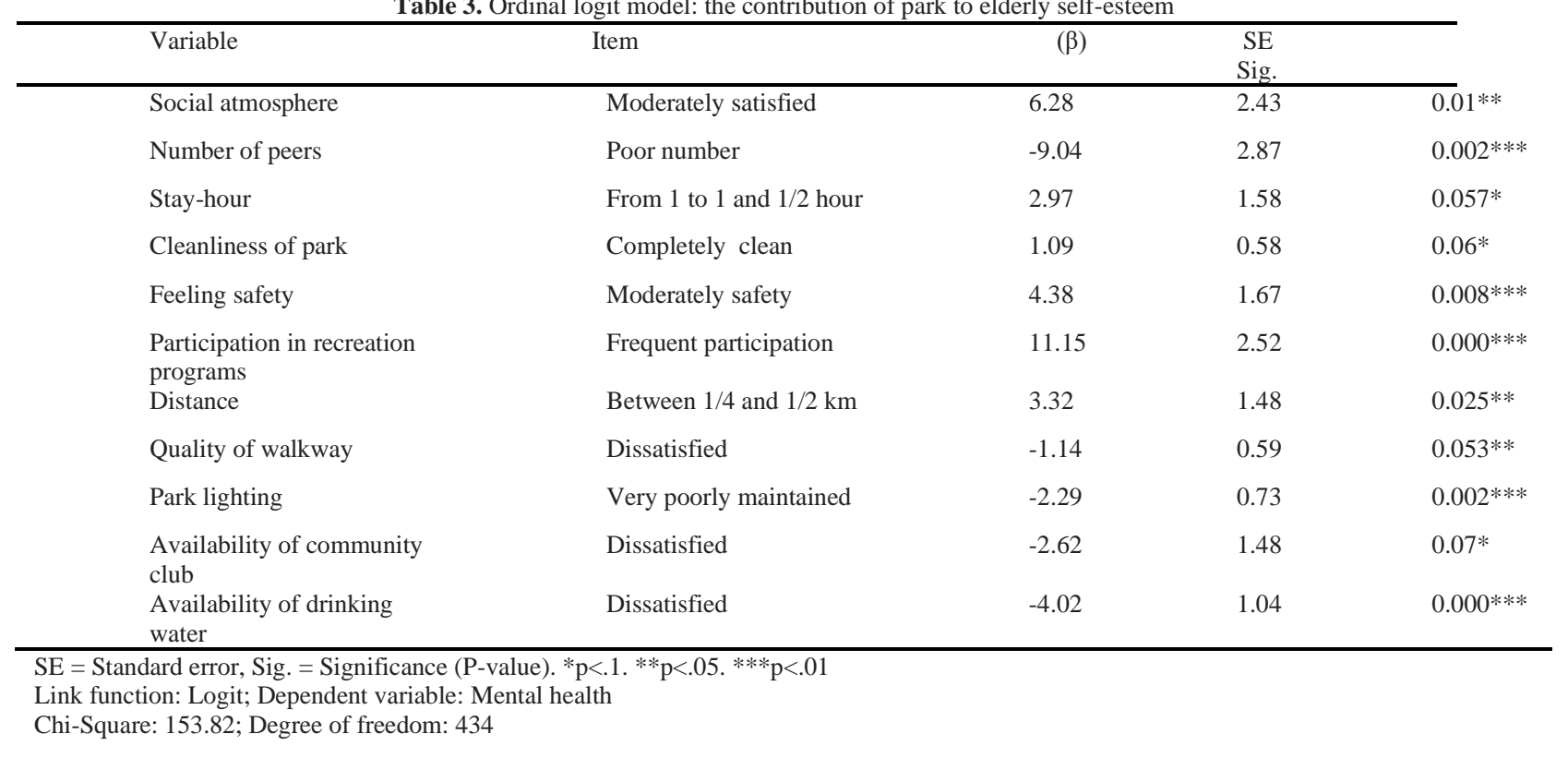

\subsection{Green space and mental health}


Table 4 the affects of green space on social inclusion, mental health, and self-esteem for the urban elderly population. We categorized the components of a park into four like social service, infrastructural amenity, safety, and walkability, which contribute to elderly people. Educational attainment had a positive effect on social inclusion, mental health, and self-esteem and the effect was significant at $1 \%$. Park user awareness was firmly linked to social inclusion ( $p$-value $=0.001)$ but weaker to self-esteem ( $p$-value=0.08). Social competence was significantly associated with mental health and self-esteem at $1 \%(B=20.05,11.84$; and p-value $=0.001)$. Elderly social inclusion and mental health were positively affected by social ties and sufficient sleep. The relationship was statistically strong as their p-values were 0.001. But they weakly effect on self-esteem $(\beta=3.95,3.64$; and $p=0.01,0.017)$. Young user behavior and the number of peers had a significant and direct impact on social inclusion, mental health, and self-esteem for the elderly population. Their impact was statistically significant at the $1 \%$ level as their $\mathrm{p}$ values are 0.001. Community inclusion, mental health, and self-esteem were positively affected by the frequency of recreation programs, participation in these programs, and staying-hour in the park. Their correlations were strongly and statistically significant at $1 \%$. The significance values of the variables were 0.001 . Their coefficient values ( $\beta$ values) were also above 10 .

Table 4. Multivariate regression analysis: the influences of green space on social inclusion, social acceptance and self-esteem

\begin{tabular}{|c|c|c|c|c|c|c|}
\hline \multirow[b]{2}{*}{ Variable } & \multicolumn{2}{|c|}{ Social inclusion } & \multicolumn{2}{|c|}{ Mental health } & \multicolumn{2}{|c|}{ Self-esteem } \\
\hline & $\beta$ & Sig. & $\beta$ & Sig. & $\bar{\beta}$ & Sig. \\
\hline \multicolumn{7}{|l|}{ Social services } \\
\hline Education & 7.49 & $0.001 * * *$ & 4.02 & $0.001 * * *$ & 1.66 & $0.019 * *$ \\
\hline User awareness & 22.68 & $0.001 * * *$ & & & 0.89 & $0.08^{*}$ \\
\hline Social competence & & & 20.05 & $0.001 * * *$ & 11.84 & $0.001 * * *$ \\
\hline Social tie & 15.32 & $0.001 * * *$ & 13.95 & $0.001 * * *$ & 3.95 & $0.01 * *$ \\
\hline Mental health & 10.771 & $0.001 * * *$ & 8.84 & $0.001 * * *$ & 3.637 & 0.017 \\
\hline Young user behavior & 16.175 & $.001 * * *$ & 20.717 & $.001 * * *$ & 22.484 & $.001 * * *$ \\
\hline Number of peers & 48.426 & $.001 * * *$ & 10.575 & $.001 * * *$ & 7.654 & $.001 * * *$ \\
\hline Social atmosphere & 58.007 & $.001 * * *$ & & & 4.13 & $.008 * * *$ \\
\hline Frequency of recreation programs & 18.953 & $.001 * * *$ & 15.472 & $.001 * * *$ & 16.69 & $.001 * * *$ \\
\hline Participation in recreation programs & 10.65 & $.001 * * *$ & 12.734 & $.001 * * *$ & 21.363 & $.001 * * *$ \\
\hline Stay-our & 8.294 & $.001 * * *$ & 13.224 & $.001 * * *$ & 12.191 & $.001 * * *$ \\
\hline \multicolumn{7}{|l|}{ Infrastructural service } \\
\hline Sitting benches & 14.653 & $.001 * * *$ & 40.41 & $.001 * * *$ & 31.757 & $.001 * * *$ \\
\hline
\end{tabular}




\begin{tabular}{|c|c|c|c|c|c|c|}
\hline Drinking water & 12.1 & $.001^{* * *}$ & 15.728 & $.001 * * *$ & 31.557 & $.001 * * *$ \\
\hline Availability of toilet & 59.528 & $.001 * * *$ & 6.565 & $.001 * * *$ & 15.355 & $.001 * * *$ \\
\hline Density of trees & 17.408 & $.001^{* * *}$ & 3.235 & $0.038^{* *}$ & 3.141 & $0.033^{* *}$ \\
\hline Availability of community club & 23.829 & $.001 * * *$ & 39.863 & $.001 * * *$ & 36.367 & $.001 * * *$ \\
\hline \multicolumn{7}{|l|}{ Safety } \\
\hline Feeling safety & 13.852 & $.001 * * *$ & 13.852 & $.001 * * *$ & 19.338 & $.001 * * *$ \\
\hline Park use rule & 29.329 & $.001 * * *$ & 40.26 & $.001 * * *$ & 37.013 & $.001 * * *$ \\
\hline Responsibility of security staff & 14.653 & $.001 * * *$ & 40.41 & $.001 * * *$ & 31.757 & $.001 * * *$ \\
\hline \multicolumn{7}{|l|}{ Walkability } \\
\hline Distance & 4.976 & $.001 * * *$ & 20.476 & $0.03 * *$ & 16.495 & $.001 * * *$ \\
\hline Quality of walkway & 7.483 & $.004 * *$ & 8.675 & $.001 * * *$ & 7.491 & $.001 * * *$ \\
\hline Road connectivity & 6.888 & $.005^{* *}$ & 8.486 & $.001 * * *$ & 8.407 & $.001 * * *$ \\
\hline Frequency of visit & 19.707 & $.001^{* * * *}$ & 46.734 & $.001 * * *$ & 41.422 & $.001 * * *$ \\
\hline
\end{tabular}

R Squared $=.795$ (Adjusted R Squared $=.750)$

Sig. $=$ Significance $($ P-value $) . * p<.1 . * * p<.05 . * * * p<.01$

Dependent variables: Social inclusion, mental health, and self-esteem

Infrastructural services were positively linked to the quality of life (social inclusion, mental health, and self-esteem) for the elderly population. Infrastructural services include seating benches, drinking water facility, the availability of toilet, the density of trees, and availability of community club (table 4). They retain a positive and statistically significant (at $1 \%$ level) association among them. The density of green trees positively affected the quality of life for the elderly population as its significance value was 0.033 . Safety was correlated to the quality of life for aged people. Feeling safety, park use rules, and the responsibility of security staff were positively and strongly linked to social inclusion, mental health, and self-esteem. Their relationship was statistically significant at $1 \%$. The walkability of a park possesses a positive effect on the quality of life for the elderly population. Short distance from home to park, quality of walkway, road connectivity to park, and the high frequency of park visits influenced the elderly quality of life. The association among them was statistically significant at $1 \%$. 


\subsection{Actualizing the effects of green space on elderly quality of life}

A refined effect of infrastructural and social services on the quality of life (self-esteem and mental health) for the elderly population was showed in figure 2. The PLS-Path model (figure 2) has been generated in multivariate analysis using study variable. A couple of variables that were not significant to fit the model were omitted. Infrastructural services and safety were correlated with social services (figure 2). Social services positively impact self-esteem linked to mental health for elderly population. Their relationships were statistically significant at $1 \%$ level (as $\mathrm{p}<0.01$ ). But individually, infrastructural services and safety were negatively correlated to self-esteem and mental health. The correlation was statistically significant at $1 \%$. Overall, social and infrastructural services were positively associated with mental health improving self-esteem for elderly population in Dhaka.

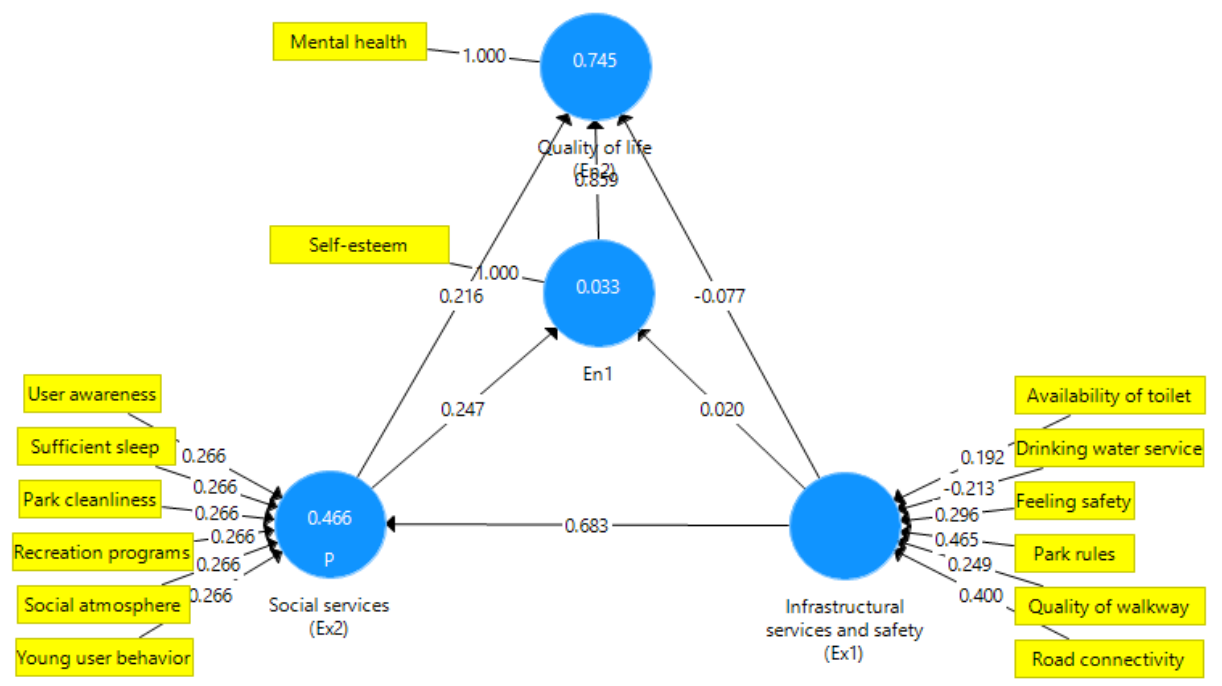

Note: Variables are significant at $1 \%$. Variables are greater than $1 \%$ were omitted from model chart. Numeric results denote coefficient values.

Figure 2. PLS-Path Model-association of quality of life with social services and infrastructural service and safety in park for elderly population 
The fitness of path model (table 5) is well. R Square value is 0.914 that is greater than $70 \%$ level. The reliability (Chronbach's alpha) score is significant as the sub-criteria of the model are greater than 0.70. Sub-criteria includes quality of life, infrastructural and social services having scores $0.92,0.69$ and 0.71 . A fit model craves a 70\% score for rho_A while it consists of $100 \%$. A good SRMR fit requires a value of less than from 0.08 to 0.10 in a conservative version [42]. Our model Square Root Mean Residual (SRMR) value is 0.081. The Normed Fit Index (NFI) value is 0.83 both in the saturated and estimated model. An NFI value usually occurs between 0 and 1 but the closer NFI to 1 is better to fit [43]. A Chi 2 value of the PLS path model approximately is $(\mathrm{N}-1) * \mathrm{~L}$, whereby $\mathrm{N}$ is the number of observations and $\mathrm{L}$ the maximum likelihood function [43]. By this definition, our Chi2 value (82.17) is well fit. d_ULS (i.e., the squared Euclidean distance) and d_G (i.e., the geodesic distance) offer the ways to calculate this discrepancy. A bootstrap running creates the confidence intervals of discrepancy values. The upper bound in confidence intervals could be larger than the original value of the authentic d_ULS and d_G fit [44] (should be at 95\% or 99\%). The d_ULS value of the model is $82 \%$ which good to fit.

Table 5. Estimation of model fit indices

\begin{tabular}{llll}
\hline Quality criteria & Sub-criteria & Value \\
\hline $\mathrm{R}^{2}$ & Social service (independent & 0.914 & \\
Chronbach's Alpha & variable) & 0.92 & \\
& Quality of life & 0.69 & \\
& Social services & 0.71 & \\
& Infrastructural services & 1.00 & \\
& Quality of life & 1.00 & \\
& Social services & 1.00 & Estimated \\
rho_A & Infrastructural services & Saturated & Model \\
& & Model & 0.081 \\
Fit summary & SRMR & 0.081 & 0.82 \\
& d_ULS & 0.82 & 0.19 \\
& d_G & 0.19 & 82.17 \\
& Chi-Square & 82.17 & 0.83 \\
\hline
\end{tabular}

\section{Discussion}

This study explored several key findings such as infrastructural services and safety measure has a positive effect on social services. Social services impact positively to boost up 
mental health building self-esteem for elderly population. The components of social services include user awareness, sufficient sleep, and the cleanliness of parks, frequent recreation programs, frequency of participation in recreation programs, friendly social atmosphere, and young user behavior. Similarly, infrastructural amenities and safety measure incorporate the availability of toilets, drinking water facility, feeling safety, park use rules, the quality of walkway, and road connectivity to parks. Green exercise (exercise in a park or a natural environment) produces a greater effect on mood and self-esteem compared to social club activities [35]. The study suggested that green space contributed to build up self-esteem and improve mood for the people of all ages through green exercise. Nevertheless, our study offered a positive contribution of green space on mental health for only elderly population. Social and infrastructural services in parks were focused on the contribution of mental health linked to selfesteem. There is a practical relationship between the availability of green space and fewer depressive symptoms. This correlation is incorporated mainly for physical activity in green space [45]. The study presented the effect of green space on mental health in terms of fewer depressive symptoms as well. However, our results investigated the contribution of green space on mental health and social welfare (self-esteem) for senior citizens. Non-motorized outdoor recreation has a significant impact on job creation, economic growth, and human health. Out-door recreation means mental and physical participation in natural settings like wild land[46]. The contribution of wildland or non-motorized out-door recreation on job creation and mental health has been emphasized where we emphasized green space and its benefits on elderly mental health linked to self-esteem.

There is an association between the viewing of green façades and an increased level of parasymantic activity. Green façade incorporates a substantial improvement of comfortable, relaxed, and natural feelings. The green façade enhances human psychological relaxation [47]. This research work demonstrated a correlation between green façade and mental relaxation for people. Our work concentrated mainly on park and mental soundness building urban elderly selfesteem. The proximity of green space with a house is linked to sound mental health, improved social support, and bodily activity. This performance has obviously differed in terms of age and sex. Senior citizens opined that societal and physical activity, social network, and clean and pleasant environment in public open spaces are important to enhance active aging and social wellbeing [48]. These findings accentuated the correlation between shared open space and 
elderly social wellbeing that is, in fact, inconsistent with our study as our study examined the benefits of public green space on elderly psychological wellbeing upon self-esteem.

Urban green space influences people positively in terms of subjective norm, behavioral control, and attitude when they use the site for socio-cultural interaction. A densely populated city like Hong Kong gets immensely beneficial for green space in terms of subjective norms and behavior [49]. Our study added self-esteem as an increased social contribution of urban green space along with the attitude, mental soundness, and behavioral control of older adults. In a park, elderly people foster their mental health through self-esteem in personal interaction with their peers. Green space provides the opportunity not only for physical exercise but also for interaction with others. Some European cities have well-managed green spaces and woodlands and have the highest level of social tie and inclusiveness. These city areas are also featured with a high level of GDP per capita [50]. With these findings, self-esteem has been extended to a new social component of green space contribution. The social tie and inclusion promote mental health improving self-esteem for urban elderly people.

Adult children's support mitigates the anxiety of elderly and conducive adults to their subjective wellbeing. When an elderly person experiences an attachment of adult children, they grew self-esteemed upon the feeling of social acceptance [51]. This study focused on the family contribution to senior citizens, but our investigation gave emphasize the benefits of urban green space on elderly psychological wellbeing linked to self-esteem. How natural society contributes to mental soundness through self-esteem for aged population has been investigated empirically. Now a day, more senior people are getting social isolated causing lower self-esteem. Urban green space benefits immensely the elderly population in terms of their social -psychological benefits. Social media use intensity is positively connected to self-esteem for an elderly population when a user receives an adequate number of 'like.' Sometimes, it hurts public acceptance and self-esteem if 'like' gets less than he expects [52]. We view that social media presently plays a vital role in social acceptance and self-esteem. Face book, Twitter, WeChat, and Instagram play a leading role all over the world. Our paper showed a positive linked of green space to mental health and self-esteem for the elderly population. We observed that a park performed a few negative roles in self-esteem for older adults. A disputed environment causes a negative condition for elderly people, when they use a park in a common interest. Green space 
possesses a relaxed setting where social media retains virtual elements that represent an indirect interaction causing sometimes dissatisfaction.

\subsection{Limitations}

This study has some limitations. We were able to access to female participants in survey less than males (women follow religious values strictly in Dhaka). Sometimes, we faced confrontation to interview in terms of the understandability of interview schedule. In this situation, we followed a pseudoscientific way to collect quality data. This study identified the positive association between green space and elderly mental health building self-esteem. This means urban green space promotes the quality of life for elderly population. Further research on the contribution of age-friendly urban park on mobility-impaired patients is required to establish an active aging.

\section{Conclusions}

Our study explored several key findings: 1) Infrastructural services and safety measure impact social services of parks; 2) Social services were positively associated with mental health boosting-up self-esteem for elderly population. The quality of social services (user awareness, sound mental health, and friendly young users' behavior, clean and friendly social atmosphere) provides satisfaction, which boost-up their mental health. Besides, mental health followed by self-esteem for senior citizens, is improved by park infrastructural amenities (the availability of toilets, drinking water facility, quality of walkway, road connectivity from home to park). Feeling safety, appropriate park rules, and the responsibility of security staff play a significant role to enhance elderly self-esteem. Self-esteem improves elderly mental health, happiness, and mitigates their anxiety. Self-esteemed people are encouraged to participate in increased sociocultural activities.

In this regard, the age-friendly urban parks are required to construct in Dhaka. The agefriendly urban park includes friendly social services, age-friendly infrastructural amenities, and safety. Mentally sound elderly populations contribute immensely to their neighborhood. They are able to assist home management process, nurturing children, computer-related job, gardening, kitchen marketing, teaching, and training, consulting, and farming. Also, when senior members of a family get quite active and self-esteemed, their families enjoy happiness. In this regard, city 
governance, urban planner, and designer can adopt the initiative to create age-friendly urban parks.

Author Contributions: All authors contributed equally to this work and were involved at every stage in its development.

Funding: This study was not funded by any institution or organization

Acknowledgements:

Conflicts of interests: The authors declare no conflict of interest.

\section{References}

1. Moksnes, U.K.; Espnes, G.A. Self-esteem and life satisfaction in adolescents-gender and age as potential moderators. Quality of Life Research 2013, 22, 2921-2928.

2. Ben-Zur, H. Coping, affect and aging: the roles of mastery and self-esteem. Personality and Individual Differences 2002, 32, 357-372.

3. Kling, K.C.; Hyde, J.S.; Showers, C.J.; Buswell, B.N. Gender differences in self-esteem: A meta-analysis. Psychological Bulletin 1999, 125, 470-500.

4. Shahi, M.; Mohammadyfar, M.A. Comparison of depression, anxiety, stress, quality of life, and alexithymia between people with type II diabetes and non-diabetic counterparts. Personality and Individual Differences 2017, 104, 64-68.

5. Arslan, G. Mediating role of the self-esteem and resilience in the association between social exclusion and life satisfaction among adolescents. Personality and Individual Differences 2019, 151.

6. Diener, E.; Emmons, R.A.; Larsen, R.J.; Griffin, S. The Satisfaction With Life Scale. Journal of Personality Assessment 1985, 49, 71-75.

7. Diener, M.L.; Diener McGavran, M.B. What makes people happy?: A developmental approach to the literature on family relationships and well-being. 2008.

8. Kintzle, S.; Barr, N.; Corletto, G.; Castro, C.A. PTSD in U.S. Veterans: The Role of Social Connectedness, Combat Experience and Discharge. Healthcare 2018, 6.

9. Duru, E. Genel aidiyet ölçeğinin psikometrik özellikleri: Geçerlik ve güvenirlik çalışması. Türk Psikolojik Danışma ve Rehberlik Dergisi 2015, 5, 37-47.

10. Malone, G.P.; Pillow, D.R.; Osman, A. The general belongingness scale (GBS): Assessing achieved belongingness. Personality and Individual Differences 2012, 52, 311-316.

11. Yildiz, M.A.; Duy, B. Adaptation of the short-form of the UCLA loneliness scale (ULS-8) to Turkish for the adolescents. Dusunen Adam 2014, 27, 194.

12. Baumeister, R.F.; Leary, M.R. The need to belong: desire for interpersonal attachments as a fundamental human motivation. Psychological bulletin 1995, 117, 497.

13. Fuente, A. de la; Chang, E.C.; Cardeñoso, O.; Chang, O.D. The psychological impact of social problem solving under stress in adults: Debased life satisfaction, heightened depressed mood, or both? Personality and Individual Differences 2019, 146, 46-52.

14. Ribeiro, S.P.; LaCroix, J.M.; De Oliveira, F.; Novak, L.A.; Lee-Tauler, S.Y.; Darmour, C.A.; Perera, K.U.; Goldston, D.B.; Weaver, J.; Soumoff, A.; et al. The Link between Posttraumatic Stress Disorder and Functionality among United States Military Service Members Psychiatrically Hospitalized Following a Suicide Crisis. Healthcare 2018, 6.

15. Williams, K.D. Ostracism: A temporal need-threat model. Advances in experimental social psychology 2009, 41, 275-314.

16. Kahn, J.H.; Hessling, R.M.; Russell, D.W. Social support, health, and well-being among the elderly: what is the role of negative affectivity? Personality and Individual Differences 2003, 35, 5-17.

17. Minkler, M. Social support and health of the elderly. 1985.

18. Bronchain, J.; Raynal, P.; Chabrol, H. The network structure of psychopathic personality traits in a non-institutionalized sample. Personality and Individual Differences 2019, 146, 41-45.

19. Newsom, J.T.; Schulz, R. Social support as a mediator in the relation between functional status and quality of life in older adults. Psychology and Aging 1996, 11, 34-44.

20. Penninx, B.W.J.H.; Van Tilburg, T.; Joan, A.J.P.; Deeg, D.J.H.; Kriegsman, D.M.W.; Van Eijk, J.Th.M. Effects of social support and personal coping resources on depressive symptoms: Different for various chronic diseases? Health Psychology 1998, 17, 551-558.

21. Filipovic Hrast Masa Social exclusion of elderly in Central and Eastern Europe. International Journal of Social Economics 2013, 40, 971-989. 
22. Grove, J.L.; Smith, T.W.; Crowell, S.E.; Williams, P.G.; Jordan, K.D. Borderline personality features, interpersonal correlates, and blood pressure response to social stressors: Implications for cardiovascular risk. Personality and Individual Differences 2017, 113, 38-47.

23. Lambrini, K. Social Exclusion of Elderly. Journal of Healthcare Communications 2016, 1.

24. Flannery, H.; Glew, S.; Brewster, A.; Christie, D. Measuring Outcomes of Psychological Well-Being within Paediatric Health Settings. Healthcare 2018, 6.

25. Bowling, A.P.; Edelmann, R.J.; Leaver, J.; Hoekel, T. Loneliness, mobility, well-being and social support in a sample of over 85 year olds. Personality and Individual Differences 1989, 10, 1189-1192.

26. Gnilka, P.B.; Broda, M.D. Multidimensional perfectionism, depression, and anxiety: Tests of a social support mediation model. Personality and Individual Differences 2019, 139, 295-300.

27. Chattu, V.K.; Manzar, Md.D.; Kumary, S.; Burman, D.; Spence, D.W.; Pandi-Perumal, S.R. The Global Problem of Insufficient Sleep and Its Serious Public Health Implications. Healthcare 2018, 7.

28. Cho, H.J.; Seeman, T.E.; Kiefe, C.I.; Lauderdale, D.S.; Irwin, M.R. Sleep disturbance and longitudinal risk of inflammation: Moderating influences of social integration and social isolation in the Coronary Artery Risk Development in Young Adults (CARDIA) study. Brain, Behavior, and Immunity 2015, 46, 319-326.

29. Kokane, A.; Pakhare, A.; Gururaj, G.; Varghese, M.; Benegal, V.; Rao, G.N.; Arvind, B.; Shukla, M.; Mitra, A.; Yadav, K.; et al. Mental Health Issues in Madhya Pradesh: Insights from National Mental Health Survey of India 2016. Healthcare 2019, 7.

30. Evans, S.; Waller, S.; Bray, J.; Atkinson, T. Making Homes More Dementia-Friendly through the Use of Aids and Adaptations. Healthcare 2019, 7.

31. Lu, L.; Lin, Y.Y. Family roles and happiness in adulthood. Personality and Individual Differences 1998, 25, $195-207$.

32. Aliyas, Z. Physical, mental, and physiological health benefits of green and blue outdoor spaces among elderly people. International Journal of Environmental Health Research 2019, 0, 1-12.

33. Browning, M.H.E.M.; Lee, K.; Wolf, K.L. Tree cover shows an inverse relationship with depressive symptoms in elderly residents living in U.S. nursing homes. Urban Forestry \& Urban Greening 2019, 41, 23-32.

34. Nawrath, M.; Kowarik, I.; Fischer, L.K. The influence of green streets on cycling behavior in European cities. Landscape and Urban Planning 2019, 190, 103598.

35. Barton, J.; Griffin, M.; Pretty, J. Exercise-, nature- and socially interactive-based initiatives improve mood and self-esteem in the clinical population. Perspect Public Health 2011, 132, 89-96.

36. Wang, X.; Wang, W.; Xie, X.; Wang, P.; Wang, Y.; Nie, J.; Lei, L. Self-esteem and depression among Chinese adults: A moderated mediation model of relationship satisfaction and positive affect. Personality and Individual Differences 2018, $135,121-127$.

37. Leary, M.R.; Tambor, E.S.; Terdal, S.K.; Downs, D.L. Self-Esteem as an Interpersonal Monitor: The Sociometer Hypothesis. Journal of Personality and Social Psychology 1995, 68, 518-530.

38. Seeland, K.; Nicolè, S. Public green space and disabled users. Urban Forestry \& Urban Greening 2006, 5, 29-34.

39. Johnson, T.P. Snowball Sampling: Introduction. In Wiley StatsRef: Statistics Reference Online; American Cancer Society, 2014 ISBN 978-1-118-44511-2.

40. Etikan, I. Comparision of Snowball Sampling and Sequential Sampling Technique. Biometrics \& Biostatistics International Journal 2016, 3.

41. Swadia, B. An International Multidisciplinary Research e-Journal Job Satisfaction among University Teachers: An Empirical Study An International Multidisciplinary Research e-Journal An International Multidisciplinary Research eJournal Section 1. 2016.

42. Fan, X.; Sivo, S.A. Sensitivity of Fit Indices to Model Misspecification and Model Types. Multivariate Behavioral Research 2007, 42, 509-529.

43. Boari, G.; Cantaluppi, G. Selection of Structural Equation Models with the PLS-VB Programme. In Proceedings of the New Developments in Classification and Data Analysis; Bock, H.-H., Gaul, W., Vichi, M., Arabie, Ph., Baier, D., Critchley, F., Decker, R., Diday, E., Greenacre, M., Lauro, C., Meulman, J., Monari, P., Nishisato, S., Ohsumi, N., Opitz, O., Ritter, G., Schader, M., Weihs, C., Vichi, M., Monari, P., Mignani, S., Montanari, A., Eds.; Springer Berlin Heidelberg: Berlin, Heidelberg, 2005; pp. 105-112.

44. Dijkstra, T.K.; Henseler, J. Consistent and asymptotically normal PLS estimators for linear structural equations. Computational Statistics \& Data Analysis 2015, 81, 10-23.

45. Patel, D.M.; Block, R.C.; Chapman, B.P.; Korfmacher, K.S.; van Wijngaarden, E. Green space and mental health symptoms in a cardiac rehabilitation population. Indoor and Built Environment 2019, 28, 1431-1440.

46. Lackey, N.Q.; Tysor, D.A.; McNay, G.D.; Joyner, L.; Baker, K.H.; Hodge, C. Mental health benefits of nature-based recreation: a systematic review. Annals of Leisure Research 2019, 0, 1-15.

47. Elsadek, M.; Liu, B.; Lian, Z. Green façades: Their contribution to stress recovery and well-being in high-density cities. Urban Forestry \& Urban Greening 2019, 46, 126446. 
48. Yung, E.H.K.; Conejos, S.; Chan, E.H.W. Social needs of the elderly and active aging in public open spaces in urban renewal. Cities 2016, 52, 114-122.

49. Wan, C.; Shen, G.Q.; Choi, S. The moderating effect of subjective norm in predicting intention to use urban green spaces: A study of Hong Kong. Sustainable Cities and Society 2018, 37, 288-297.

50. Valente, D.; Pasimeni, M.R.; Petrosillo, I. The role of green infrastructures in Italian cities by linking natural and social capital. Ecological Indicators 2020, 108, 105694.

51. Zhang, Z.; Hayward, M.D.; Yu, Y.-L. Life Course Pathways to Racial Disparities in Cognitive Impairment among Older Americans. J Health Soc Behav 2016, 57, 184-199.

52. Wang, Y.; Nie, R.; Li, Z.; Zhou, N. WeChat Moments use and self-esteem among Chinese adults: The mediating roles of personal power and social acceptance and the moderating roles of gender and age. Personality and Individual Differences 2018, 131, 31-37. 